Revista Destaques Acadêmicos, Lajeado, v. 12, n. 3, 2020. ISSN 2176-3070

DOI: http://dx.doi.org/10.22410/issn.2176-3070.v12i3a2020.2641

http://www.univates.br/revistas

\title{
PERFIL EPIDEMIOLÓGICO DE PACIENTES POLITRAUMATIZADOS ATENDIDOS EM UMA UNIDADE DE TERAPIA INTENSIVA ADULTO NO INTERIOR DO RIO GRANDE DO SUL
}

\author{
Deise Schossler ${ }^{1}$, Paula Michele Lohmann², Luís Felipe Pissaia ${ }^{3}$
}

\begin{abstract}
Resumo: O trauma é considerado um problema de saúde pública por acometer um número significativo de pessoas diariamente e gerando a necessidade de internações prolongadas e cuidados intensivos. O objetivo deste estudo foi identificar o perfil epidemiológico de pacientes politraumatizados internados em uma Unidade de Terapia Intensiva adulto de um hospital no interior do Rio Grande do Sul. Estudo transversal e exploratório realizado a partir de uma amostra de 451 prontuários de pacientes politraumatizados, dos quais 62 foram selecionados para a análise. As variáveis analisadas neste estudo foram: a natureza do trauma, dados referentes ao sexo, faixa etária, características do evento. Foram estimadas as proporções com intervalos de confiança de 95\% (IC 95\%) das características de cada item avaliado. Os resultados demonstraram que a maioria são homens jovens em idade produtiva e a principal causa dos acidentes foi o Trauma Crânio Encefálico (TCE). O impacto das infecções associado às características sociodemográficas e circunstanciais são fatores importantes no desfecho final da vítima politraumatizada. A partir do panorama constatado neste estudo, as características clínicas e a gravidade dos pacientes politraumatizados internados na UTIs, devem ser consideradas para a elaboração do plano de cuidados, assim como investigar possíveis particularidades da população atendida.
\end{abstract}

Palavras-chave: Unidade de terapia intensiva. Centro de terapia intensiva. Unidade de terapia intensiva de adulto. Cuidados críticos.

1 Enfermeira, pós-graduanda em Centro Cirúrgico, CME e SR, Faculdade de Ciências da Saúde - Hospital Moinhos de Vento, Porto Alegre/RS. deise.s@universo.univates.br

2 Enfermeira, doutoranda em Ambiente e Desenvolvimento e docente do Curso de Enfermagem da Universidade do Vale do Taquari - Univates, Lajeado/RS. paulalohmann@univates.br

3 Enfermeiro, doutorando em Ensino e docente da Universidade do Vale do Taquari - Univates, Lajeado/RS. lpissaia@universo.univates.br 


\section{INTRODUÇÃO}

O trauma é uma lesão representada por variações estruturais ou desequilíbrios fisiológicos decorrentes da exposição a várias formas de energia mecânica, térmica, elétrica, química e irradiações (BAITELLO, 2017). Este evento está entre a principal causa de morte e incapacidades em pessoas jovens, sendo considerado como fatores etiológicos os acidentes de trânsito e de trabalho. Ele pode ser definido como qualquer alteração à saúde, causada por fatores externos como: acidente automobilístico, agressão física, ferimento por arma de fogo ou arma branca, queda e acidente de trabalho (BAITELLO, 2017; MUNIE ET AL., 2019).

Anualmente a Organização Mundial de Saúde (OMS) identifica a ocorrência de 1,5 milhões de óbitos por violência. No ano de 2004 mais de 5 milhões de óbitos ocorreram por conta de eventos traumáticos, sendo que destas, de maneira aproximada, um quarto foi decorrente de acidentes de trânsito. Os eventos traumáticos estão associados à várias internações hospitalares no Brasil e no mundo, muitos deles carecem de uma Unidade de Terapia Intensiva (UTI), visto que esses pacientes são submetidos a procedimentos e cirurgias invasivas, e que necessitam de um cuidado especializado e prolongado para sanar a situação (MUNIE ET AL., 2019).

A maioria dos casos de trauma, são acometidos jovens, causando incapacidade física e intelectual ou até mesmo óbito, gerando um custo social altíssimo, além de dados irreparáveis para o grupo familiar e comunitário (PLUMMER; HERMANIDES; DEANE, 2019). Tal constatação reafirma o problema de saúde pública que é considerado o acidente de trânsito, incluindo as questões socioeconômicas de perda de renda e capacidade de estar ativo no mercado de trabalho e desenvolvendo suas funções sociais.

Em consonância a isso, as lesões procedentes destes acidentes geram um custo -elevado na saúde, com a recuperação e nos tratamentos oriundos de seus agravos. Os acidentes de trânsito se caracterizam como a principal causa de morte entre pessoas de 15 e 29 anos, e $90 \%$ das mortes por acidente no mundo ocorrem em países de baixa e média renda. Estima-se que, sem as devidas ações, até 2030 os acidentes rodoviários se tornem a sétima causa de morte (ONU, 2018).

No Estado do Rio Grande do Sul entre os anos de 2003 a 2016 foram registrados 41.268 mil óbitos por acidentes de trânsito, sendo que o índice mais elevado ocorreu no ano de 2010, onde se teve um aumento considerável de fatalidades (VAN STEEN ET AL., 2019).

Neste cenário, a UTI configura-se como um espaço no qual se desempenha o papel decisivo na chance de sobrevida dos pacientes gravemente enfermos vítimas de trauma (JARDEN et al., 2019). A UTI, que recebe pacientes gravemente feridos e doentes, é considerada por vários autores como uma unidade onde ocorrem muitos casos de politraumatizados, e os 
pacientes internados nesta unidade requerem cuidados complexos e intensivos (PADILHA et al., 2017).

Sendo assim, considera-se que a internação por politrauma é um problema de saúde pública, pois acomete uma parcela da população consideravelmente jovem. Além de gerar custos para o tratamento, gerando afastamento do trabalho, prejuízos de saúde permanentes e exclusão social em algumas situações. Neste contexto, o objetivo deste estudofoi identificar o perfil epidemiológico de pacientes politraumatizados internados em uma UTI adulto de um hospital no interior do Rio Grande do Sul.

\section{MÉTODOS}

Trata-se de uma pesquisa de abordagem exploratória e descritiva, de coleta de dados transversal e análise de cunho quantitativa. $O$ estudo foi realizado em um hospital de médio porte localizado em um município do interior do estado do Rio Grande do Sul, Brasil. O hospital é uma instituição filantrópica, de direito privado e possui aproximadamente 200 leitos, destes, 20 leitos são de UTI adulto.

A coleta de dados ocorreu em 451 prontuários de pacientes internados na UTI adulto durante o ano de 2017. Os critérios de inclusão foram os prontuários de pacientes internados na UTI adulto, durante o ano de 2017, sendo estes, vítimas de algum tipo de trauma. Como critérios de exclusão, identificou-se prontuários incompletos que impossibilitaram a coleta das informações. Após a aplicação dos critérios de inclusão e exclusão, a amostra final compôs-se por 62 prontuários.

O período de coleta de dados foi de agosto a outubro de 2018, utilizandose um instrumento elaborado e organizado pela pesquisadora por meio do software Microsoft Excel 2016. O instrumento continha a identificação do prontuário, sexo, idade, procedência, tipo de trauma, principais intercorrências decorrentes do trauma (neste item registrava-se: Parada Cardiorrespiratória, cirurgia (tipo), infecção pós-trauma (se houve em decorrência do trauma) e período de internação (PEREIRA et al., 2018).

As variáveis analisadas neste estudo foram: a natureza do trauma, dados referentes ao sexo, faixa etária, características do evento, sendo a análise por frequência.

Para a realização da pesquisa os pesquisadores obtiveram a carta de anuência da instituição hospitalar alvo de estudo. Durante todo o processo foram respeitados os critérios éticos para pesquisas com seres humanos, preconizados pela Resolução 466/12, restringindo-se o acesso dos prontuários somente aos pesquisadores e em local autorizado e sigiloso, além de manter o resguardo da identificação de cada paciente (BRASIL, 2013). 


\section{RESULTADOS}

Com base na análise dos 62 prontuários, identificou-se que a maioria das vítimas eram homens, num total de 52 , representando $83,9 \%$ e 10 mulheres $(16,1 \%)$, sendo que a idade variou de 16 e 88 anos. A idade das vítimas de trauma atendidas na UTI, de maior ocorrência dos incidentes, foi a faixa etária entre os 22 aos 27 anos (12 indivíduos), ou seja, 19,3\%.

O tipo de trauma de maior ocorrência, 22 (35,5\%) pacientes, foi de Trauma Crânio Encefálico (TCE), 19 (30,6\%) de TCE e fraturas, seis $(9,7 \%)$ de fraturas, cinco $(8,1 \%)$ de TCE e politrauma, três $(4,8 \%)$ de fraturas e pneumotórax, dois $(3,2 \%)$ de ferimento por arma de fogo, um $(1,6 \%)$ de TCE e pneumotórax, um $(1,6 \%)$ de TCE e trauma torácico, um $(1,6 \%)$ de ferimento por arma branca, um $(1,6 \%)$ de politrauma, um $(1,6 \%)$ de TCE e ferimento por arma de fogo.

Nas principais intercorrências $23,5 \%$, ou seja 23 pacientes não tiveram nenhuma intercorrência, $14(14,2 \%)$ apresentaram infecção, nove $(9,2 \%)$ evoluíram para traqueostomia, nove $(9,2 \%)$ desenvolveram pneumonia, oito $(8,2 \%)$ necessitaram de laparotomia, oito $(8,2 \%)$ sofreram intervenção cirúrgica, oito $(8,2 \%)$ com diagnóstico de pneumonia associada à ventilação mecânica (PAVM), quatro $(4,1 \%)$ necessitaram de craniotomia, três $(3,1 \%)$ tiveram morte cefálica $(\mathrm{MC})$, três $(3,1)$ apresentaram parada cardiorrespiratória, um $(1,0 \%)$ com pneumotórax, um $(1,0 \%)$ Síndrome da Angústia Respiratória do Adulto (SARA), um $(1,0 \%)$ insuficiência renal aguda (IRA), nos demais houve as intervenções foram: de uma $(1,0 \%)$ drenagem de hematoma, uma $(1,0 \%)$ cranioplastia, uma $(1,0 \%)$ ileostomia e um $(1,0 \%)$ dreno de tórax.

Sobre as principais intercorrências associadas, quatro pacientes $(18,2 \%)$ foram de PAVM e traqueostomia e infecção, dois $(9,1 \%)$ de PAVM e traqueostomia, dois $(9,1 \%)$ craniotomia, e infecção e pneumonia, um $(4,5 \%)$ de pneumonia e infecção, um $(4,5 \%)$ de PAVM e PCR e IRA e traqueostomia, um $(4,5 \%)$ cirurgia e ME, um $(4,5 \%)$ de pneumonia e traqueostomia e dreno de tórax, um $(4,5 \%)$ de laparotomia e infecção, um $(4,5 \%)$ de laparotomia e ileostomia, um $(4,5 \%)$ de laparotomia e craniotomia, um $(4,5 \%)$ de craniotomia e infecção, um $(4,5 \%)$ de MC e craniotomia, um $(4,5 \%)$ de infecção e pneumonia e cirurgia e traqueostomia, um $(4,5 \%)$ de pneumonia e SARA, um $(4,5 \%)$ de pneumonia e infecção e traqueostomia, um $(4,5 \%)$ de PCR e infecção, um $(4,5 \%)$ de PCR e infecção e pneumonia.

Quanto ao agente causador, $15(24,2 \%)$ pacientes sofreram queda, $14(22,6 \%)$ acidente com moto, dez $(16,1 \%)$ acidente com carro, nove $(14,5 \%)$ atropelamento, sete $(11,3 \%)$ vítimas de violência, três $(4,8 \%)$ acidente com bicicleta, um $(1,6 \%)$ mergulho em rio, um $(1,6 \%)$ acidente com trator, um $(1,6 \%)$ acidente durante atividade física.

Dos prontuários analisados, oito destes, ou seja 12,9\% indicaram óbito dos pacientes, e $57(87,1 \%)$ tiveram alta da UTI para unidade de internação 
clínica por apresentar melhora no quadro de saúde. A idade média dos pacientes foi de 20 anos e um tempo de internação na UTI de 9 dias.

\section{DISCUSSÃO}

O trauma é definido como toda e qualquer lesão provocada à um indivíduo, levando para um conjunto de perturbações causadas de modo súbito por agente físico, que apresenta etiologia, natureza e extensão bem variadas, nos diferentes segmentos corporais (DATASUS, 2008).

Os resultados mostraram um perfil de pacientes jovens $(19,3 \%)$, a maioria do sexo masculino $(83,9 \%)$, em idade produtiva, vítimas de acidentes de trânsito, politraumatizados com necessidade de internação na UTI. Esse perfil vem de encontro com os dados de 2008 do Ministério da Saúde (MS) quanto às causas externas por internação na população jovem (15 a 39 anos) (DATASUS, 2008).

$\mathrm{Na}$ amostra analisada, os principais mecanismos de trauma foram em sua maioria, condutores de motocicleta, seguido por quedas e automóveis. Além disto, é expressivo o número de acidentes nesta mesma faixa etária. Observandose os dados nacionais do ano de 2008 que apresentam as quedas como principal mecanismo de trauma, seguida pelos acidentes automobilísticos e agressões. A mortalidade por acidentes de trânsito e armas de fogo, apresentam mais de 50\% dos óbitos (DATASUS, 2008; SILVA, 2012).

Os dados do Sistema de Informações sobre Mortalidade (SIM) do DATASUS/Brasil, em 2015, na região Sul apresenta o número de óbitos por tipo de trauma. Segundo os dados do órgão, as quedas representam 78 casos, sendo acidentes de transporte um total de 148, afogamento e submersões acidentais com 25 situações, exposição à fumaça, ao fogo e às chamas com 2 indivíduos acometidos, envenenamento, intoxicação por ou exposição a substâncias nocivas em 3 situações, lesões autoprovocadas voluntariamente em 100 casos, agressões em 169 momentos, todas as outras causas externas somaram 57 e causas externas de morbidade e mortalidade somaram 706 de acometidos (DATASUS, 2015).

Desta forma o estudo apresentou como o tipo de trauma com maior ocorrência, o Trauma Crânio Encefálico (TCE) como também associado a fraturas. Esse achado demonstra o impacto relacionado aos tipos de causas que estão interligadas às lesões, estas que podem ser mecânica, química, térmica, elétrica ou por irradiação, podendo ser intencional ou não intencional. ${ }^{7}$ Além disso, o TCE é considerado a principal causa de morte e sequela em crianças e adultos jovens nos países industrializados ocidentais (KRAUS, 1993; MCARTHUR; CHUTE; VILLABLANCA, 2004).

Segundo estudos epidemiológicos realizados no Brasil nas últimas décadas, observa-se um aumento nas taxas de mortalidade, invalidez e morbidade causadas pelo trauma, o que idealiza um grave problema social 
no país. Existem três tipos de mortalidade no trauma: a primeira ocorre contiguamente após o trauma, muitas vezes na cena do acidente, decorrentes de lesões gravíssimas. Na segunda situação ocorre o óbito após duas a quatro horas do incidente, com agravamento de lesões relacionadas à insuficiência respiratória como exemplo, pneumotórax hipertensivo, ou relacionado a eventos hemorrágicos como ruptura de fígado, baço, múltiplas fraturas. Ou até mesmo lesões cranianas como hematoma subdural, casos estes que necessitam de averiguação imediata visando melhorar a sobrevida desses pacientes, reduzindo sequelas e prevenindo óbitos. A terceira causa ocorre dias ou semanas após o evento traumático conveniente a sepses que ocorrem durante a internação hospitalar deste paciente (BAITELLO, 2017; PAIVA et al., 2010).

É possível observar que os acidentes de trânsito são responsáveis pelo vultuoso número de óbitos. Caso o óbito não seja imediato, a vítima apresenta politraumatismos, ou seja, múltiplas lesões, que são determinados por agentes mecânicos, acarretando o comprometimento de vários órgãos e sistemas resultante de lesões. Lesões estas que acarretam na gravidade do estado de saúde do paciente, necessitando de atendimento imediato, evitando sequelas futuras e o agravamento do quadro (CHARLLUB PEREIRA BEZERRA et al., 2015).

A principal finalidade do atendimento ao paciente politraumatizado é a diminuição e se possível eliminação das sequelas do trauma, realizando um atendimento de emergência inicial, sendo esta a avaliação primária, identificando outras lesões na avaliação secundária. É essencial o conhecimento do politrauma por parte dos profissionais para atuar em situações que apresentem risco iminente de morte, bem como o suporte necessário que uma vítima de politrauma necessita (CHARLLUB PEREIRA BEZERRA et al., 2015; PAIVA et al., 2010).

Neste sentido, a internação em UTI adulto se destina exclusivamente à reabilitação de pacientes graves, em estado crítico que carecem de um cuidado em tempo contínuo, com uma monitorização adequada, possibilitando ao profissional o atendimento rápido e eficaz as possíveis intercorrências que podem surgir, garantindo um atendimento satisfatório. Neste estudo as principais intercorrências foram por infecção, o que demonstra o impacto da internação, como também as principais intercorrências associadas, foram de PAVM, traqueostomia e a infecção (COLPAN et al., 2005; PAIVA et al., 2010; RODRIGUEZ et al., 2016).

A taxa de infecção foi de $14,2 \%$, o que representou 14 pacientes dos 62 pesquisados. A referida taxa está de acordo com os indicadores. O sítio de infecção mais comum foi pelas pneumonias. Sendo que as principais intercorrências envolveram a pneumonia associada a ventilação mecânica, a necessidade de traqueostomia e intervenção cirúrgica. $\mathrm{O}$ tempo médio de internação foi de 9,0 dias na UTI adulto. A mortalidade foi de 12,9\% entre 
os pacientes que envolvia várias intercorrências no politrauma e parada cardiorrespiratória.

Avaliando os achados deste estudo, corrobora-se com as informações acerca das infecções hospitalares (IHs) que ocorrem na UTI, primariamente, por estarem associadas à gravidade clínica dos pacientes. Uso de procedimentos invasivos, como cateter venoso central, sonda vesical de demora e ventilação mecânica, uso de várias medicações e imunossupressores, bem como o período de internação prolongado, colonização por microrganismos resistentes, prescrição de antimicrobianos e o próprio ambiente da unidade, que favorece a seleção natural de microrganismos (MCARTHUR; CHUTE; VILLABLANCA, 2004; PAIVA et al., 2010).

As pneumonias somam aproximadamente $31 \%$ de todas as infecções em UTI, segundo dados do National Nosocomial Infections Surveillance System (NNIS), assim vários autores afirmam que a pneumonia nosocomial é o segundo sítio de IHs mais comum e a principal causa de morte neste meio. Essa informação está em conformidade aos achados deste trabalho, em que as pneumonias somaram $9,2 \%$ enquanto principal intercorrência e $18 \%$ quando associada dos casos de IHs, sendo menos recorrente que as outras intercorrências durante o período de internação (MESIANO; MERCHÁN-HAMANN, 2007).

Dentre os $62(100 \%), 54(87,1 \%)$ tiveram alta da UTI e $8(12,9 \%)$ foram a óbito, sendo que destes pacientes $23(23,5 \%)$ não apresentaram nenhuma intercorrência e $14(14,2 \%)$ desenvolveram algum tipo de infecção. Dado semelhante é encontrado em outros trabalhos que descrevem a relação positiva entre o aumento da mortalidade e pacientes com diagnóstico de IH (ESPÓSITO; LEONE, 2007).

Acredita-se que o investimento em políticas públicas voltadas para a orientação no trânsito bem como a cultura de paz seja necessário e de maior investimento para a prevenção e redução dos números de acidentes de trânsito, da violência e, consequentemente, da morbi-mortalidade. Além disso, concluise que os resultados deste estudo contribuem para reflexão sobre o controle de infecções no contexto da UTI adulto, ratificando a extrema necessidade de um programa de controle de IHs efetivo com o envolvimento de toda a equipe de saúde. Visto que o estudo demonstrou que as IH estão associadas aos desfechos associados, tais como os riscos do paciente politraumatizado, mortalidade e ocorrência de microrganismos resistentes.

A partir do panorama constatado neste estudo, as características clínicas e a gravidade dos pacientes politraumatizados internados na UTIs, devem ser consideradas para a elaboração do plano de cuidados, assim como investigar possíveis particularidades da população atendida. Bem como, os princípios e diretrizes do SUS, devem ser considerados e respeitados pela equipe multiprofissional que ali atua, garantindo que o atendimento ao paciente em UTI adulto, seja direcionado à busca da qualidade da assistência. 


\section{CONCLUSÃO}

O perfil geral das vítimas de politrauma analisado no estudo não corresponde ao perfil geral nacional que é de população idosa, masculina e vítima de quedas. Já no que se refere ao perfil do trauma na população jovem, verificou-se a concordância ao encontrado nos dados epidemiológicos e na literatura disponível atualmente.

Evidencia-se que os acidentes automobilísticos e a violência interpessoal continuam a crescer, afetar e matar principalmente a população masculina jovem e economicamente ativa. Ou seja, envolve e reflete em valores para a sociedade e para o Sistema Único de Saúde (SUS).

Este estudo serve como instrumento de aplicação e qualificação da ciência no âmbito da saúde, articulando novos pensamentos e quebras de padigma com a finalidade de estimular a realização de novos estudos para aprofundamento nessa área em específico. Em suma, o desacomodar das informações reveladas e discutidas nesse estudo, são capazes de sensibilizar os diversos meios acadêmicos para estruturação e qualificação da assistência em saúde.

\section{REFERÊNCIAS}

BAITELLO, A. L. Atendimento ao paciente vítima de trauma: abordagem para o clínico. 1. ed. Rio de Janeiro: Atheneu, 2017.

BRASIL. Conselho Nacional de Saúde. Resolução n 466, de 12 de dezembro de 2012. Aprova normas regulamentadoras de pesquisas envolvendo seres humanos. Diário Oficial da União, Brasília, DF, 13 jun. 2013. Seção 1, p 59.

CHARLLUB PEREIRA BEZERRA, Y. et al. Politraumatismo: conhecimento dos estudantes de enfermagem acerca das práticas assistenciais. Revista de Enfermagem UFPE On Line, v. 9, n. 11, p. 9817-9825, nov. 2015. Disponível em: <https:/ / periodicos.ufpe.br/revistas/revistaenfermagem/article/view/10773>. Acesso em: 19 abr. 2018.

COLPAN, A. et al. Evaluation of risk factors for mortality in intensive care units: a prospective study from a referral hospital in Turkey. American Journal of Infection Control, v. 33, n. 1, p. 42-47, Feb. 2005. Available from: <https://www.ajicjournal. org/article/S0196-6553(04)00607-8/fulltext>. Access in: 2 May 2018.

DATASUS. Informações de saúde epidemiológicas e morbidade: causas externas por internação, 2008. Banco de dados. Disponível em: <http://tabnet.datasus.gov.br>. Acesso em: 05 nov. 2018.

DATASUS. SIM-Sistema de Informações de Mortalidade, 2015. Bando de dados. Disponível em: <http://www2.datasus.gov.br/DATASUS/index.php?area=060701>. Acesso em: 23 abr. 2018. 
ESPÓSITO, S.; LEONE, S. Antimicrobial treatment for Intensive Care Unit (ICU) infections including the role of the infectious disease specialist. International Journal of Antimicrobial Agents, v. 29, n. 5, p. 494-500, May 2007. Available from: <https:/ / www.sciencedirect.com/science/article/abs/pii/S0924857907000532?via\%3Dihub>. Access in: 23 Apr. 2018.

JARDEN, R. J. et al. Intensive care nurses' well-being: A systematic review. Australian Critical Care, v. 33, n. 1, p. 106-111, Jan. 2019. Available from: <https:/ / pubmed.ncbi. nlm.nih.gov/30679048/>. Access in: 22 Apr. 2018.

KRAUS, J. F. Epidemiology of head injury. In: COOPER, P. R. (editor). Head injury. 3rd. ed. Baltimore: Willians \& Wilkins, 1993.

McARTHUR, D. L.; CHUTE, D. J.; VILLABLANCA, J. P. Moderate and severe traumatic brain injury: epidemiologic, imaging and neuropathologic perspectives. Brain Pathology, v. 14, n. 2, p. 185-194, Apr. 2004. Available from: <https:/ / onlinelibrary.wiley.com/doi/abs/10.1111/j.1750-3639.2004.tb00052.x>. Access in: 17 May 2018.

MESIANO, E. R. A. B.; MERCHÁN-HAMANN, E. Bloodstream infections among patients using central venous catheters in intensive care units. Revista LatinoAmericana de Enfermagem, Ribeirão Preto, v. 15, n. 3, p. 453-459, June 2007. Available from: <https://www.scielo.br/scielo.php?script=sci_arttext\&pid=S010411692007000300014\&lng=en\&tlng=en>. Access in: 24 Apr. 2018.

MUNIE, S. et al. 220: Medical management of spontaneous celiac artery dissection in the surgical intensive care unit. Critical Care Medicine, v. 47, n. 1, p. 9-15, Jan. 2019. Available from: <https://journals.lww.com/ccmjournal/Citation/2019/01001/220 MEDICAL_MANAGEMENT_OF_SPONTANEOUS_CELIAC.186.aspx>. Access in: 25 Apr. 2018.

ORGANIZAÇÃO DAS NAÇÕES UNIDAS (ONU). Brasil. Acidentes de trânsito matam 1,25 milhão de pessoas no mundo por ano, 2018. Site. Disponível em: $<$ https://nacoesunidas.org/acidentes-de-transito-matam-125-milhao-de-pessoas-nomundo-por-ano/>. Acesso em: 19 jun. 2020.

PADILHA, K. G. et al. Carga de trabalho de enfermagem, estresse/burnout, satisfação e incidentes em unidade de terapia intensiva de trauma. Texto \& Contexto - Enfermagem, Florianópolis, v. 26, n. 3, 2017. Disponível em: <https:/ / www.scielo. br/scielo.php?script=sci_arttext\&pid=S0104-07072017000300322\&lng=pt\&tlng=pt $>$. Acesso em: 24 abr. 2018.

PAIVA, L. et al. Experiência do paciente politraumatizado e suas consequências. Revista Latino-Americana de Enfermagem, v. 18, n. 6, p. 221-1228, nov./dez. 2010. Disponível em: <http:/ / www.revistas.usp.br/rlae/article/view/4278>. Acesso em: 27 abr. 2018.

PEREIRA, A. S. et al. Metodologia da pesquisa científica [recurso eletrônico]. 1. ed. Santa Maria, RS: UFSM/NTE, 2018. Disponível em: <https:/ / repositorio.ufsm. 
br/bitstream/handle/1/15824/Lic_Computacao_Metodologia-Pesquisa-Cientifica. pdf?sequence=1>. Acesso em: 15 abr. 2018.

PLUMMER, M. P.; HERMANIDES, J.; DEANE, A. M. Incretin physiology and pharmacology in the intensive care unit. Critical care clinics, v. 35, n. 2, p. 341-355, Apr. 2019. Available from: <https://pubmed.ncbi.nlm.nih.gov/30784614/>. Access in: 10 May 2018.

RODRIGUEZ, A. H. et al. Características epidemiológicas e causas de óbitos em pacientes internados em terapia intensiva. Revista Brasileira de Enfermagem, Brasília, v. 69, n. 2, p. 1-8, mar./abr. 2016.

SILVA, E. S. Reanimação no trauma: manejo e técnica. São Paulo: Martinari, 2012.

VAN STEEN, S. C. et al. The association of intravenous insulin and glucose infusion with intensive care unit and hospital mortality: a retrospective study. Annals of intensive care, v. 9, art. 29, 2019. Available from: <https://pubmed.ncbi.nlm.nih. gov/30742240/>. Access in: 10 May 2018. 